\title{
DIVERSIFICAÇÃO E EXPANSÃO DO DIREITO INTERNACIONAL: RISCOS OU DIFICULDADES?
}

\author{
DIVERSIFICATION AND EXPANSION OF INTERNATIONAL LAW: RISKS OR \\ DIFFICULTIES?
}

Rodrigo Bastos Raposo ${ }^{1}$

RESUMO: Entre 2000 e 2006 a Comissão de Direito Internacional das Nações Unidas empreendeu um estudo acerca do fenômeno da fragmentação do direito internacional. O estudo foi marcado a princípio por preocupações essencialmente negativas acerca do fenômeno, que, se aprofundando a partir do final da segunda guerra mundial, estaria a modificar e desnaturar a ordem jurídica internacional, podendo mesmo desintegrá-la em múltiplos subsistemas desconectados. No entanto, ao longo do desenvolvimento das discussões sobre o assunto, emergiu a percepção de que o fenômeno da fragmentação era também um sinal de vitalidade e crescimento do direito internacional e que, conquanto trouxesse desafios à manutenção da coerência e sistematicidade do mesmo, era essencialmente um fenômeno positivo de expansão do império do direito e um fruto da busca por maior eficácia do sistema por seus próprios atores.

PALAVRAS-CHAVE: Fragmentação do direito internacional. Expansão do direito internacional. Diversificação do direito internacional.

ABSTRACT: Between 2000 and 2006 the International Law Commission undertake a study about the phenomenon of the fragmentation of international law. In the beginning, the study presented a negative perception of the phenomenon, which, having deepened since the end of World War II, would be modifying and changing the nature of the international legal order, ensuing even the risk of its disintegration in a multitude of disconnected subsystems. Although, in the course of the discussions

\footnotetext{
${ }^{1}$ Doutorando em Direito (UERJ). Mestre em Direito (UFSC). Bacharel em Direito (UFMA). Advogado (OAB/MA 5.389). Professor de Direito Internacional (IBMEC/RJ; UNDB/MA). Endereço eletrônico: rodrigobastosraposo@ hotmail.com
} № $40 \mid$ p. $184-229$ | AGO - OUT 2013 
on the subject, the perception of fragmentation as a sign of vitality and growing of international law has arisen and, as long as it had brought challenges in keeping the coherent and systemic character of international law, it was, at the same time, an essentially positive phenomenon of rule of law expansion and a consequence of the continuous search, by international actors, for a more efficient international juridical system.

KEY-WORDS: Fragmentation of International Law. Expansion of International Law. Diversification of International Law.

\section{CONSIDERAÇÕES INICIAIS}

A hipótese central deste artigo é que o fenômeno da fragmentação do direito internacional não representa uma ameaça, mas sim o fruto de um processo de expansão e diversificação desse ramo do direito que suscita constantemente o desenvolvimento de soluções técnicas que preservem a organicidade do sistema jurídico internacional em meio à pujança de seu desenvolvimento.

Essa hipótese foi investigada pela Comissão de Direito Internacional das Nações Unidas entre 2000 e 2006, por um Grupo de Estudos cujo objeto de investigação foi primeiro designado Risks of the Fragmentation of International Law e, posteriormente Fragmentation of International Law: Difficulties Arising from the Diversification and Expansion of International Law. Evidentemente que os estudos realizados pela Comissão não tem nenhum caráter dogmático ou valor de verdade, estando sujeitos à avaliação, crítica e refutação por parte da comunidade acadêmica. Por conta disso, o Relatório do Grupo de Estudos e suas Conclusões constituem um ponto de partida idôneo para estudos sobre o tema e foram por isso escolhidos como o fio condutor deste trabalho.

Quanto aos resultados alcançados, cabe esclarecer que o Grupo de Estudos sobre a fragmentação do direito internacional apresentou-os em duas partes: o relatório analítico, que reuniu os estudos parciais dos diversos membros e foi finalizado por Martti Koskenniemi, presidente do Grupo; e as conclusões, 
apresentadas sob a forma de uma série composta por quarenta e duas proposições sintéticas, que resumiram o relatório analítico e as discussões do Grupo.

O objetivo geral deste artigo é apresentar as Conclusões do Grupo de Estudos levando em conta elementos do Relatório e alguns aportes doutrinários, para tanto, a exposição foi ordenada em três partes. A primeira parte procede ao resgate histórico dos trabalhos do Grupo de Estudos, desde a inclusão do tópico fragmentação no plano de trabalho da Comissão de Direito Internacional, em 2000, até a apresentação dos resultados finais, em 2006 e foi desenvolvido a partir dos relatórios da Comissão, compreendendo a origem dos trabalhos, as preocupações e os debates que acompanharam a sua produção. A segunda parte apresenta os resultados obtidos pela Comissão, destacando as quarenta e duas conclusões e o relatório sintético apresentado ao Sexto Comitê (Jurídico) da Assembleia Geral das Nações Unidas, a exposição considerou o conteúdo do relatório analítico consolidado pelo presidente do Grupo de Estudos dedicado à matéria no âmbito da Comissão. A terceira parte foi dedicada ao tratamento dado ao tema e aos trabalhos da Comissão pela doutrina, buscando perceber como a percepção do fenômeno foi se formando e modificando ao longo do tempo e atentando também para as questões julgadas mais relevantes e polêmicas.

Como considerações finais, ponderou-se que a fragmentação é melhor descrita como um processo de expansão e diversificação do direito internacional e que, embora imponha desafios técnicos aos seus operadores, não representa uma ameaça de colapso desse sistema jurídico, mas, ao contrário, manifesta a satisfação de demandas dos atores internacionais por crescente regulação e ordenação de suas relações conforme seus interesses peculiares. Ou seja, o processo de fragmentação apenas reflete o pluralismo existente na sociedade internacional, a multiplicidade de temas e problemas e a consequente multiplicidade de soluções jurídicas e de medidas para efetivá-las. As discussões acadêmicas sobre o fenômeno, no mesmo passo, correspondem às preocupações relativas à unidade, coerência e efetividade do sistema e, em seus aspectos mais operacionais, dizem respeito à adaptação e elaboração de ferramentas jurídicas capazes de enfrentar uma realidade jurídica internacional profundamente enraizada na tradição e na história, mas que ao mesmo tempo, precisa dar respostas a situações substancialmente novas. 


\section{HISTÓRICO DOS TRABALHOS DO GRUPO DE ESTUDOS}

Na 52a Sessão da Comissão de Direito Internacional, em 2000, sob a presidência de Chusei Yamada, do Japão, decidiu-se pela inclusão do tópico Risks ensuing from the fragmentation of international law em seu plano de trabalho de longo prazo. Naquele momento foi pontuado que o tema provavelmente não seria passível de codificação ou desenvolvimento progressivo; ainda assim, a Comissão considerou que a pesquisa poderia trazer uma contribuição significativa para a compreensão de um assunto de crescente importância para o direito internacional (ROSENSTOCK, 2001, p. 226).

A Comissão constatou que o tema Risks ensuing from the fragmentation of international law era diferente de outros até então enfrentados. No entanto, a opinião da Comissão era que o assunto envolvia matéria de crescente importância para o Direito Internacional e que seria relevante realizar estudos para sua melhor compreensão. Além disso, a Comissão ponderou que o tema, embora envolvesse uma abordagem diferente da normalmente adotada - i.e. codificação - estava inserido dentro da competência da Comissão definida em seus estatutos (ILC, 2000, p. 132).

Na 54a Sessão, em 2002, presidida por Robert Rosenstock, dos Estados Unidos, a Comissão iniciou os trabalhos preliminares sobre a fragmentação do direito internacional. Para isso, constituiu um grupo de estudo, presidido por Bruno Simma, sobre Risks of the Fragmentation of International Law, mesmo nome do estudo de viabilidade apresentado por Gerhard Hafner na 52a Sessão, em 2000, o qual foi utilizado para delimitar a discussão (ROSENSTOCK; GRIMES, 2003, p. 162, 166).

O estudo apresentado por Hafner em 2000 afirmava que, em tempos recentes, principalmente a partir do final da Guerra Fria, o direito internacional tornara-se sujeito a uma fragmentação maior do que em períodos anteriores. Este efeito era atribuído principalmente ao aumento da regulação internacional, tendo como fatores adicionais a crescente fragmentação política aliada ao crescimento da interdependência regional e global em áreas como economia, meio ambiente, 
energia, recursos naturais, saúde e proliferação de armas de destruição em massa (HAFNER, 2000, p. 143).

O ambiente político relativamente estável da Guerra Fria oferecia resistência à separação política e geográfica de seus componentes. Esse cenário mudou na década de 1990, com o fim do sistema político bipolar que estruturava as relações internacionais deste o fim da II Guerra Mundial. A dissolução da União Soviética fez emergir com intensidade movimentos nacionalistas em todo o mundo e, a cada ruptura, a própria resistência do sistema político e jurídico internacional à ruptura de suas partes componentes foi enfraquecendo (REISMAN, 1990, p. 864).

Nesse processo o sistema global tornou-se crescentemente complexo e interdependente, com isso, a soberania do Estado-Nação encontra-se na berlinda. Todos os países são atualmente mais vulneráveis às ações e decisões tomadas fora de suas fronteiras que em momentos anteriores da história. O sistema internacional contemporâneo se depara com o paradoxo de uma fragmentação política crescente justaposta a crescentes relações de interdependência nos níveis regional e global em áreas como economia, meio ambiente, energia, recursos naturais, saúde e a crescente preocupação com a disseminação de armas de destruição em massa. Além disso, a soberania e a eficácia das ações governamentais são ainda mais dificultadas pelo crescimento de divisões dentro dos próprios Estados. A partir da década de 1990, o maior crescimento no número de membros das Nações Unidas foi devido à dissolução de países como a União Soviética, a lugoslávia e outros. Do mesmo modo, essas divisões internas, ligadas a questões étnicas, religiosas, raciais, econômicas e territoriais chegam a desafia a viabilidade de alguns Estados e tornam muito mais difícil a efetividade das ações de governo. Esses desafios à soberania dos Estados por vezes são acrescidos de outro elemento, que é a sobreposição de questões domésticas e questões internacionais, assim, a medida que decisões e eventos atravessam fronteiras e produzem efeitos imediatos em pessoas em diferentes países, surgem demandas por soluções que transcendem os governos nacionais, ou então por soluções no plano local, a serem adotadas por unidades administrativas menores e mais próximas das populações locais, de modo que com frequência crescente a resolução de problemas cria tensões entre os interesses das populações locais, os interesses nacionais e emergentes interesses 
regionais ou globais, ainda difusos, mas cuja influência não pode mais ser ignorada (FRY, 1994, p. 303).

Desde o final da guerra fria, o sistema internacional tem atravessado mudanças em um ritmo mais acelerado que em períodos anteriores. A rigidez do sistema bipolar, que estabilizou as relações internacionais por décadas, deu lugar a um cenário político aberto e instável. A falência ou pujança do conceito de soberania é objeto de debate, pois alguns dos mais relevantes desafios apresentados aos Estados são baseados na afirmação da soberania ou pretensões de autodeterminação de suas unidades constituintes, por vezes colocadas em um contexto de integração regional. Ao mesmo tempo, Estados e governos buscam maiores graus de cooperação e colaboram para a edificação de instituições internacionais que deem conta de estabelecer uma ordem internacional mais estável e pacífica. Desta forma, os campos de oposição e cooperação encontram-se hoje misturados tanto em função das agendas políticas quanto em função da divisão de atribuições entre Estados e Organizações Internacionais (DELBRÜCK, 1993, p. 705).

Esse contexto influenciou fortemente o estudo preliminar sobre os riscos decorrentes da fragmentação, levando Hafner a afirmar que não há um sistema homogêneo de direito internacional e que o direito internacional existente não consiste em uma ordem jurídica, mas é composto principalmente por diferentes sistemas parciais, produzindo um sistema não-organizado (unorganized system), composto por partes cujos comportamentos não apresentam regularidade ou uniformidade e que são estruturados cada qual à sua maneira. Hafner afirmava ainda que o sistema jurídico internacional é composto de elementos instáveis e imprevisíveis, cada qual estruturado à sua maneira, de modo que dificilmente se pode falar de homogeneidade no direito internacional. Tal sistema é cheio de sistemas universais, regionais e mesmo bilaterais e de subsistemas de diferentes níveis, entre os quais existem graus muito variados de integração jurídica (HAFNER, 2000, p. 144).

Ainda assim, o direito internacional composto por estes subsistemas jurídicos distintos, de comportamento imprevisível, possui indubitavelmente um aspecto positivo, que é o de promover o império do direito nas relações internacionais. Por outro lado, está exposto ao risco de atritos e contradições entre REVISTA DO DIREITO UNISC, SANTA CRUZ DO SUL № 40| p. $184-229$ | AGO - OUT 2013 
essas várias regulações jurídicas, e mesmo à possibilidade dos Estados terem de cumprir obrigações mutuamente excludentes, o que acarretaria inevitavelmente responsabilidade internacional. Eis onde Hafner situou o papel da Comissão de Direito Internacional, cuja missão principal é a codificação e o desenvolvimento progressivo do direito internacional, de acordo com o art. 13 da Carta das Nações Unidas, no interesse da estabilização do direito e, consequentemente, das relações internacionais. Uma vez que a fragmentação ameaça a estabilidade, a coerência e o caráter sistêmico do direito internacional, o estudo dos meios de superar seus efeitos adversos seria parte das tarefas da Comissão (HAFNER, 2000, p. 144).

Ainda na 54a Sessão, em 2002, quando se decidiu empreender estudos preliminares sobre a fragmentação, manifestou-se preocupação acerca da conotação negativa dos termos risks e fragmentation, presentes no trabalho de Hafner e adotados na designação do tópico de estudo, os quais poderiam ser vistos como uma manifestação de contrariedade em relação à expansão do direito internacional para novas áreas. Com isso, o Grupo de Estudos sugeriu a mudança do título do tópico para Fragmentation of International Law: Difficulties Arising from the Diversification and Expansion of International Law, e prosseguiu com o intento de expor os aspectos positivos e negativos do fenômeno (ROSENSTOCK; GRIMES, 2003, p. 167).

As expressões diversificação e expansão do direito internacional, constantes no subtítulo do Grupo de Estudos representam de modo mais acurado o objeto de estudo, com a vantagem de afastar a conotação negativa do termo fragmentação, sem deixar de ressaltar os desafios e dificuldades decorrentes do fenômeno.

A sugestão de alteração do título foi aceita pela Comissão em suas reuniões de 6 e 7 de agosto de 2002, que emendou e adotou o relatório apresentado pelo Grupo de Estudos (ILC, 2002, p. 237).

O Grupo concordou que a fragmentação não é um fenômeno novo e que é tanto inerente ao direito de um mundo fragmentado quanto uma consequência natural da expansão do direito internacional; logo, a abordagem do tema deveria necessariamente considerar os mecanismos já existentes desenvolvidos pelo direito internacional ao longo de sua evolução histórica. A fragmentação impõe de fato riscos e desafios à unidade e coerência do direito internacional, e o trabalho da REVISTA DO DIREITO UNISC, SANTA CRUZ DO SUL № 40| p. $184-229$ |AGO - OUT 2013 
Comissão deveria ter em mente o enfrentamento e superação destas questões. Por outro lado, também há aspectos positivos a serem considerados, entre eles: a expansão do direito internacional é um sinal de sua vitalidade; a proliferação de normas, regimes e instituições podem fortalecer o direito internacional; com sua expansão e diversificação, o direito internacional atinge áreas outrora ignoradas; é vantajosa a existência de uma pluralidade de vozes e valores jurídicos e de um sistema policêntrico de direito internacional (ILC, 2002, p. 238-239).

Do mesmo modo, dada a atipicidade do assunto, que reunia diversas questões de difícil solução, a Comissão resolveu não aplicar os seus métodos de trabalho usuais - esboçar um tratado ou uma declaração - e preferiu submeter um relatório à Assembleia Geral que apresentasse uma perspectiva do estado do direito internacional, com ênfase em sua crescente fragmentação (ROSENSTOCK; GRIMES, 2003, p. 167).

Discutiu-se ainda a metodologia a adotar, e a Comissão decidiu, ao fim, por uma abordagem mais exploratória e que desse alguma flexibilidade para a definição futura dos contornos da pesquisa. Entretanto, foi excluído desde logo o tema da criação e relacionamento entre instituições judiciais internacionais, pois, segundo o Relatório de 2002, houve um entendimento no Grupo de Estudos de que a Comissão não deveria lidar com questões relativas à criação ou ao relacionamento entre instituições judiciais internacionais; o Grupo, entretanto, ponderou que, na medida que as mesmas regras ou regras semelhantes de direito internacional poderiam ser qualificadas e aplicadas de maneira diferente por instituições judiciais, os problemas decorrentes destas divergências deveriam ser enfrentados (ILC, 2002, p. 240).

Nas recomendações do Grupo de Estudos foi definido que o objetivo dos trabalhos deveria auxiliar os operadores jurídicos internacionais a lidar com as consequências da diversificação do direito internacional, sendo para tanto definidos cinco tópicos de estudo: papel e alcance da regra lex specialis e a questão dos regimes auto-contidos, interpretação dos tratados à luz das regras relevantes dos direito internacional aplicáveis às relações entre as partes, aplicação de tratados sucessivos relativos à mesma matéria, modificação de tratados multilaterais apenas entre parte de seus membros, e hierarquia jurídica no direito internacional (ILC, 2002, p. 241). 
Pelos tópicos escolhidos pode-se perceber que desde o início a Convenção de Viena sobre Direito dos Tratados seria utilizada como um marco para o desenvolvimento dos estudos da Comissão, tanto que na designação de quase todos os tópicos mencionados acima é feita referência expressa a dispositivos da Convenção. O tema da interpretação enseja menção ao artigo 31.3.c, o da aplicação de tratados sucessivos relativos ao mesmo tema é ligado ao artigo 30 e o da modificação de tratados multilaterais por apenas algumas de suas partes é vinculado ao artigo 41. Apenas os temas da função do preceito lex specialis e da hieraquia entre as normas de direito internacional não foram expressamente relacionados a dispositivos da Convenção, o primeiro por não haver sido alvo de codificação e o segundo por ter sido tratado apenas de forma incipiente (ODENDAHL, 2012, p. 506).

Finalmente, o Grupo de trabalho concordou com o desenvolvimento de uma caixa de ferramentas destinada a auxiliar na solução de problemas práticos decorrentes das incongruências e conflitos entre os regimes e normas jurídicas existentes. Os trabalhos deveriam ser iniciados pela primeira das ferramentas idealizadas: a norma lex specialis, sua função e alcance e a questão dos regimes especiais (self-contained regimes). Foi definido que o presidente do Grupo de Estudos apresentaria um estudo sobre este tópico no ano seguinte (ROSENSTOCK; GRIMES, 2003, p. 167; ILC, 2002, p. 242).

Na 54ํㅗ Sessão, em 2003, a Comissão substituiu o presidente do Grupo de Estudos, Bruno Simma, que fora eleito juiz da Corte Internacional de Justiça, por Martti Koskenniemi. Em suas reuniões, o Grupo procurou reestruturar suas tarefas tendo em vista o restante daquele quinquênio, a encerrar-se em 2006, distribuindo os temas definidos em 2002 entre seus membros e empreendendo uma discussão preliminar sobre a função e escopo da norma lex specialis e a questão dos regimes especiais, a partir de esboço apresentado pelo presidente (ILC, 2003, p. 268).

Nas discussões, percebeu-se que era possível estabelecer duas perspectivas distintas com relação à fragmentação, uma institucional e outra substancial. A primeira era relativa à coordenação e hierarquia entre instituições e à necessidade dos vários atores, particularmente os tribunais, atentarem para as decisões uns dos outros. A segunda era relativa ao processo pelo qual a substância do direito internacional em si mesma poderia haver se fragmentado em regimes especiais entre os quais haveria uma ausência de coerência ou cujas disposições № 40| p. $184-229$ | AGO - OUT 2013 
seriam contraditórias. Tal distinção era importante para determinar como a Comissão desenvolveria o estudo do tema; nesse momento, foi rememorado e mantido o posicionamento do Grupo na 54a Sessão, de não tratar da criação de ou do relacionamento entre instituições judiciais internacionais (ILC, 2003, p. 269).

Essa decisão implicava em não considerar que mudanças poderiam ser feitas no funcionamento das cortes internacionais, justamente os órgãos encarregados de produzir as decisões relativas à aplicação do direito internacional. Tampouco deveria o Grupo enfocar o aperfeiçoamento das interações entre as cortes internacionais, devendo ater-se a analisar como o direito material funciona e como este funcionamento poderia gerar critérios para trazer ordem a um cenário fragmentado de decisões internacionais (LEATHLEY, 2007, p. 260).

No entanto, quais seriam as razões por traz de tal decisão? Leathley aponta em primeiro lugar a ausência de autoridade da Comissão de Direito Internacional para, no exercício de seu mandato de avaliar diversos temas do direito internacional com vistas ao seu desenvolvimento e codificação, propor uma mudança tão significativa na estruturação da comunidade jurídica internacional, uma vez que os Estados membros das Nações Unidas jamais desejaram atribuir poderes legislativos ou assemelhados à Comissão, quanto mais delegar a ela a tarefa de preparar propostas polêmicas para reestruturação da ordem internacional. Uma segunda razão para evitar tratar da fragmentação em sua dimensão institucional é que isso implicaria fazer escolhas difíceis e controversas, afinal, quais cortes deveriam ser escolhidas para figurar no topo ou na base de um sistema hierarquizada de instituições jurisdicionais internacionais? Um terceiro motivo seria que, ainda que a Comissão tivesse o atrevimento de fazer uma proposta relativa à hierarquia entre as instituições judiciárias internacionais, não haveria nenhuma segurança de que estas viessem a aceitá-la, inclusive porque uma posição de superioridade reduziria a possibilidade da corte escolhida evitar determinados assuntos considerados delicados ou políticos, ensejando questionamentos sobre o perfil da mesma, sua legitimidade e representatividade em relação ao conjunto de seus jurisdicionados. Em quarto lugar, a Comissão já vinha consideravelmente sobrecarregada com a tarefa de enfrentar os aspectos substanciais da fragmentação, o que tornava inconveniente abrir uma nova frente de trabalho. Um quinta possível justificativa, seria que um relatório que contivesse uma proposta REVISTA DO DIREITO UNISC, SANTA CRUZ DO SUL № 40| p. $184-229$ | AGO - OUT 2013 
clara de hierarquização substancial das normas internacionais, uma vez apresentado, permitiria maior convergência entre as decisões dos tribunais, ou seja, uma hierarquia substantiva, por si mesma, já faria muito para equacionar as inconsistências que a definição de uma hierarquia institucional buscaria remediar. Por fim, uma sexta ponderação seria a de quê a complexidade do Direito Internacional, por si, justificaria a existência de diversas cortes para considerar diferentes casos de formas específicas, adequadas a seus contextos peculiares e que seria inerente ao direito internacional que duas ou mais cortes pudessem lidar com o mesmo assunto, cada qual à sua maneira, isso seria, inclusive, a beleza do direito internacional (LEATHLEY, 2007, p. 268-270).

Complementando as razões acima expostas, convém acrescentar que a Comissão foi constantemente cobrada, ao longo de seus trabalhos sobre a fragmentação do Direito Internacional, para entregar um trabalho objetivo, de utilidade prática e para evitar perder-se em divagações teórico-filosóficas. Essas cobranças eram provenientes do Comitê Jurídico da Assembleia Geral das Nações Unidas, o Sexto Comitê, sob cuja supervisão e a partir de cujas demandas a Comissão de Direito Internacional exerce suas atribuições. Assim sendo, também sob o aspecto político-institucional dentro das Nações Unidas, o Grupo de Estudos não possuía a latitude de atuação necessária para definir e alargar a seu bel prazer o escopo ou a duração de suas atividades (SIXTH COMMITTE, 2004, p. 49-50).

Com relação aos aspectos substanciais, constatou-se a existência de pelo menos três diferentes padrões de conflitos que poderiam interessar ao estudo da fragmentação: o conflito entre diferentes interpretações do direito internacional geral, exemplificado pela aplicação de critérios distintos nos casos Tadic (International Criminal Tribunal for the former Yugoslavia) e Nicarágua v. Estados Unidos (Corte Internacional de Justiça); o conflito decorrente do desvio em relação ao direito geral em virtude da aplicação de direito especial, como no caso Belilos; o conflito proveniente da contradição entre dois campos especializados do direito internacional, como ilustrado pelos casos Tuna/Dolphins disputes (GATT) e Beef Hormones (OMC) (ILC, 2003, p. 270-271).

Em seu relatório, o Grupo de Estudos também destacou a importância da Convenção de Viena sobre Direito dos Tratados como uma moldura apropriada para o desenvolvimento das investigações (ILC, 2003, p. 272). 
No relatório de 2003 consta também a divisão dos tópicos de estudo entre os membros do Grupo, com a previsão de sua conclusão em 2005, sendo que o ano de 2006 ficou reservado para a consolidação do relatório final envolvendo todos os tópicos (ILC, 2003, p. 273-274).

Consta do relatório da 56 Sessão, de 2004, a realização de oito encontros entre os membros do Grupo de Estudos, bem como a apresentação do relatório preliminar sobre a regra lex specialis e dos esboços sobre aplicação de tratados sucessivos, sobre interpretação de tratados à luz da regras relevantes de direito internacional aplicáveis às relações entre as partes, sobre a modificação de tratados multilaterais entre apenas algumas de suas partes, e sobre hierarquia no direito internacional, tarefas estas distribuídas no ano anterior (ILC, 2004, p. 282).

Em suas discussões, o Grupo reafirmou a intenção de estudar a fragmentação em seus efeitos positivos e negativos como uma expressão da diversificação e expansão do direito internacional. Foi observado que o Sexto Comitê (Questões Jurídicas) da Assembleia Geral das Nações Unidas apoiou a ênfase do estudo em questões substanciais bem como a decisão de utilizar a Convenção de Viena sobre Direito dos Tratados como base para as considerações acerca da fragmentação (ILC, 2004, p. 283).

O Sexto Comitê também recomendou que, em seu trabalho final, a Comissão evitasse embarcar em um exercício puramente acadêmico e preparasse algumas orientações (guidelines) sobre o tema. No debate que se seguiu, alguns membros do Comitê fizeram notar que o tema era particularmente amplo e teórico e que não serviria de base para o esboço de artigos ou orientações (SIXTH COMMITTE, 2004, p. 49-50).

Em vista disso, o Grupo deliberou submeter à Comissão, em 2006, um documento composto por duas partes: a primeira contendo um estudo sobre o tema da fragmentação e a segunda um resumo conciso de suas conclusões e, se apropriado, orientações sobre como lidar com as dificuldades decorrentes do fenômeno (ILC, 2004, p. 283).

Houve nesse momento uma certa diferença de visões entre o Sexto Comitê e a Comissão, o primeiro demandando a produção de um guia com instruções substanciais para lidar com a fragmentação e o segundo ponderando quanto à dificuldade de dar orientação normativa às conclusões de um estudo que № $40 \mid$ p. $184-229$ | AGO - OUT 2013 
por sua natureza era eminentemente teórico. A solução adotada, de produção de dois documentos, procurou conciliar as necessidades de elaborar um estudo mais extenso e analítico, que reunisse as contribuições dos membros do Grupo de Estudos, e de apresentar ao Sexto Comitê um apanhado sucinto que se aproximasse tanto quanto possível da formulação de orientações.

Em 2005, os estudos distribuídos para realização pelos membros do Grupo de Estudos em 2003 estavam prontos para serem discutidos. Novamente, foram realizados oito encontros, que apreciaram um memorando sobre regionalismo, a luz do estudo sobre a regra lex specialis e sobre regimes auto-contidos; e estudos sobre interpretação de tratados, aplicação de tratados sucessivos, modificação de tratados multilaterais e hierarquia no direito internacional, apresentados em conformidade com os esboços submetidos em 2004 (ILC, 2005, p. 205).

Dentre os estudos apresentados, foram destacados o realizado por Martti Koskenniemi sobre a máxima lex specialis e regimes especiais (self-contained regimes) e o realizado por Zdzislaw Galicki sobre hierarquia no direito internacional. A partir do trabalho de Koskenniemi, o Grupo de Estudos concluiu que não há hierarquia entre as fontes do direito internacional, mas que os atores internacionais tendem a dar preferência à aplicação de normas mais específicas. Do mesmo modo, não existem regimes inteiramente autônomos (entirely self-contained), pois todos eles operam dentro da moldura do direito internacional geral. O estudo de Galicki tratou especificamente de jus cogens, obrigações erga omnes e do artigo 103 da Carta das Nações Unidas. A partir desse trabalho, o Grupo de Estudos reconheceu o caráter especial dessas obrigações em relação a outras fontes do direito internacional, porém, não estabeleceu qualquer hierarquia entre as três categorias, reconhecendo, entretanto, que o caráter erga omnes de certas obrigações não é um princípio hierárquico. O Grupo também decidiu não tentar elaborar um catálogo de normas de jus cogens (MATHESON, 2006, p. 422).

Na visão de Matheson, o Grupo de Estudos acertou ao não avançar ainda mais nesses pontos, particularmente em relação ao conteúdo e efeito jurídico da categoria jus cogens, que são assuntos controvertidos tanto na prática estatal quanto no debate acadêmico, e cuja consideração pela Comissão seria precipitada naquele momento. $O$ mesmo poder-se-ia dizer quanto a hipotéticos conflitos entre normas de jus cogens e as decisões tomadas pelo Conselho de Segurança REVISTA DO DIREITO UNISC, SANTA CRUZ DO SUL № 40| p. $184-229$ | AGO - OUT 2013 
conforme o Capítulo VII da Carta das Nações Unidas. No atual contexto, é mais adequado que a Comissão colabore com o aperfeiçoamento da compreensão, pelos atores internacionais, dos temas sob estudo e de suas implicações práticas; parece ter sido nesse sentido que se desenvolveram as atividades do Grupo de Estudos (MATHESON, 2006, p. 422).

Com relação à abordagem, o Grupo de Estudos reafirmou a orientação adotada de focalizar os aspectos materiais da fragmentação e de não se deter na chamada fragmentação institucional. Em relação às recomendações do Sexto Comitê, o Grupo reiterou seu propósito de atingir um resultado que possuísse valor prático e oferecesse recursos que permitissem aos operadores do direito internacional em vários níveis lidar com obrigações conflitantes ou sobrepostas. Quanto ao produto final de suas atividades, o Grupo reafirmou o intento de oferecer um documento de autoria coletiva em duas partes: uma delas um estudo analítico relativamente extenso, compilando as contribuições dos diversos membros, a partir, principalmente, da Convenção de Viena sobre Direito dos Tratados; e a outra um apanhado sintético das conclusões, orientações e princípios que surgiram a partir das discussões em grupo, com ênfase em orientações para refletir e lidar com as questões da fragmentação na prática jurídica (ILC, 2005, p. 206-207).

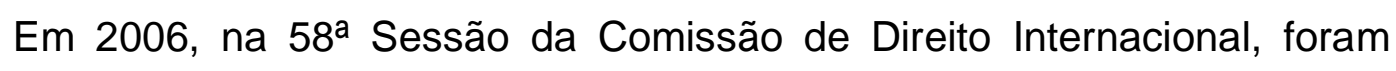
submetidos os resultados finais do Grupo de Estudos sobre fragmentação. Como previsto no ano anterior, foram apresentados um relatório analítico, mais extenso, e um conjunto com 42 conclusões, que sintetizam o trabalho realizado e suas conclusões (ILC, 2006, p. 420-423).

São esses resultados que serão apresentados a seguir, os quais serão referidos como: "relatório analítico", quando for mencionado o relatório compilado e finalizado pelo presidente do Grupo, Martti Koskenniemi (KOSKENNIEMI, 2006); e "conclusões", quando for referido o documento finalizado pelo conjunto do Grupo de Estudos (ILC, 2006).

\section{RESULTADOS DOS TRABALHOS DO GRUPO DE ESTUDOS}

Quando os resultados dos trabalhos foram analisados pela Comissão, um dos membros do Grupo de Estudos propôs que fosse feita uma distinção entre REVISTA DO DIREITO UNISC, SANTA CRUZ DO SUL № 40| p. $184-229$ | AGO - OUT 2013 
fragmentação positiva e negativa, a qual não foi aceita. Na sequência, a Comissão tomou ciência das conclusões e as encaminhou à atenção do Sexto Comitê (Jurídico) da Assembleia Geral das Nações Unidas. A Comissão solicitou que o estudo analítico fosse disponibilizado em seu site e publicado em seu anuário (ILC, 2006, p. 402).

Martii Koskenniemi dividiu o relatório analítico em sete partes e um apêndice. Nas duas primeiras partes introduziu o trabalho e apresentou sua concepção do fenômeno da fragmentação. Nas quatro partes em que dividiu o desenvolvimento do trabalho, abordou as formas pelas quais as ferramentas do direito internacional podem ser empregadas para resolver os problemas técnicos de aplicação do direito internacional ocasionados pela fragmentação. Ele concluiu reiterando suas conclusões mais gerais e apresentando uma proposta de estudos para o campo do direito internacional. No apêndice, ele destacou o papel da Convenção de Viena sobre Direito dos Tratados como uma base sobre a qual pode se estruturar o estudo do conflito de leis tal como ele se apresenta no contexto da fragmentação.

As conclusões apresentaram os resultados das discussões finais do Grupo de Estudos e seguiram aproximadamente a divisão temática do relatório analítico, dividindo-se em: 1. Geral; 2. Máxima lex specialis derogat legi generali; 3. Regimes especiais; 4. Artigo 31(3)(c) da Convenção de Viena sobre Direito dos Tratados; 5 . Conflitos entre normas sucessivas; 6 . Hierarquia no direito internacional. Em sua redação foi adotada a forma de tópicos numerados, os quais são reproduzidos e comentados a seguir.

\subsection{Considerações gerais}

A primeira parte das conclusões trouxe as considerações gerais do Grupo de Estudos acerca do fenômeno da fragmentação e é composta por quatro assertivas.

A primeira conclusão afirma que o direito internacional é um sistema jurídico cujas normas atuam e devem ser interpretadas umas em relação às outras, considerando sua hierarquia, seus graus de generalidade e especificidade e o momento de sua produção. Enquanto sistema, o direito internacional não é uma coleção aleatória de normas, ao contrário, existem relações significativas entre elas, 
que podem existir em níveis hierárquicos mais ou menos elevados, cuja formulação pode envolver maior ou menor grau de especificidade e cuja validade pode ser estabelecida em diferentes momentos no tempo (ILC, 2006, p. 407).

O mais importante nessa conclusão é a afirmação do caráter sistêmico do direito internacional, o que contrasta com a posição firmada pelo Prof. Gerhard Hafner no estudo de viabilidade mencionado no início deste trabalho. O preceito remete à necessidade de considerar o direito internacional em seu contexto normativo, ressaltando que ele não é um conjunto disperso, desconexo ou incoerente de normas jurídicas, pois há relações hierárquicas, de generalidade/especialidade e de temporalidade que se articulam para conferir-Ihe unidade sistêmica.

Já a segunda conclusão trata dos conflitos, aparentes ou reais, quando há necessidade de determinar, em certas situações, qual a relação precisa entre duas ou mais normas válidas aplicáveis prima facie à mesma situação. Na aplicação do direito internacional, por vezes é necessário determinar qual a relação entre duas ou mais regras e princípios válidos e aplicáveis à certa situação. Nesse caso, as relações que se estabelecem podem ser de interpretação ou de conflito. No primeiro caso, uma norma contribui para a definição da extensão e sentido da outra, definindo sua aplicação, ou esclarecendo seu significado, atualizando-a ou modificando-a, situação em que ambas as normas são aplicadas em conjunto. No segundo caso, as duas normas são válidas e aplicáveis, mas determinam decisões incompatíveis, neste caso será necessário escolher uma delas, empregando as orientações básicas contidas na Convenção de Viena sobre Direito dos Tratados (ILC, 2006, p. 407-408).

O postulado afirma que quando duas normas são válidas e aplicáveis a certa situação, é necessário determinar a relação entre elas. Por vezes, é possível, mediante um exercício hermenêutico, estabelecer a interação entre as normas e aplicá-las em conjunto, coerentemente. Em outras situações, pode ocorrer das normas aplicáveis apontarem para soluções distintas, quando então será necessário determinar critérios para aplicação de uma em detrimento da outra, com o auxílio das normas existentes na Convenção de Viena sobre Direito dos Tratados.

A Convenção de Viena tem sua importância ressaltada na terceira conclusão, em particular os dispositivos relativos à interpretação de tratados. As REVISTA DO DIREITO UNISC, SANTA CRUZ DO SUL № 40| p. $184-229$ | AGO - OUT 2013 
relações entre normas em conflito devem ser determinadas por meio da aplicação direta ou analógica das regras contidas na Convenção, particularmente seus artigos 31 a 33. A Convenção de Viena sobre Direito dos Tratados procurou definir as relações entre duas ou mais normas entre si e definiu que as normas devem ser interpretadas de acordo com as disposições da própria Convenção, particularmente as disposições relativas à interpretação de tratados (ILC, 2006, p. 408).

O Grupo de Estudos concluiu que as orientações contidas nos artigos 31 a 33 da Convenção de Viena devem ser aplicadas diretamente, quando se cuidar de tratados, ou por analogia, quando o cotejo se der com os produtos de outras fontes. Essa afirmativa irá ecoar por todas as demais conclusões, sendo também a pedra de toque do relatório analítico. Deve-se ressaltar aqui que os desafios trazidos pela expansão e diversificação do direito internacional não são sintomas de desintegração ou colapso, o que por vezes é entendido a partir do termo fragmentação, cuja conotação negativa foi razão de discussão desde a inclusão do tópico no programa de trabalho da Comissão de Direito Internacional. Os desafios existentes são desafios hermenêuticos, são problemas técnicos que reclamam a atuação do jurista para dar feições harmônicas e funcionais ao produto jurídico de relações políticas, econômicas e culturais dos mais diferentes atores e nas mais diversas escalas concebidas pelo agir humano.

Essa afirmação é corroborada na quarta e última conclusão da parte geral, ao afirmar que as relações entre duas ou mais normas aplicáveis à mesma situação devem ser, tanto quanto possível, observadas de acordo com o princípio da harmonização e interpretadas de modo a construir um conjunto unificado de obrigações compatíveis. Este princípio, geralmente aceito, consiste em que, quando diversas normas referem-se a um mesmo assunto, as mesmas devem ser interpretadas de modo a constituir um conjunto unificado de obrigações (ILC, 2006, p. 408).

Eis o princípio da harmonização, pelo qual se compreende que os atores internacionais não assumem obrigações contraditórias e que respeitam o conjunto do direito ao desenvolver novas relações e compromissos. Portanto, deve-se assumir sempre que há uma harmonia subjacente ao sistema jurídico e buscar soluções que privilegiam a construção de um sistema normativo coerente. 
Pela leitura dessas quatro primeiras assertivas pode-se constatar que 0 Grupo de trabalho sobre a fragmentação do direito internacional, embora ciente do fenômeno da expansão e diversificação normativa e dos desafios que este traz aos juristas, seguiu descrevendo o direito internacional como um sistema coerente, cujas normas estão relacionadas por relações de compatibilidade e dotado de ferramentas técnicas, sintetizadas nos dispositivos da Convenção de Viena sobre Direito dos Tratados, capazes de orientar a resolução de conflitos normativos.

\subsection{Lex specialis derogare lege generali}

O segundo item das conclusões tratou da máxima lex specialis derogat legi generali, a máxima é uma técnica comumente aceita para resolução de conflitos no direito internacional, que sugere a aplicação da norma mais específica sempre que duas ou mais normas forem aplicáveis à mesma situação. A máxima é uma técnica geralmente aceita para interpretar e resolver conflitos de normas no âmbito do Direito Internacional, apontando que sempre que duas ou mais normas se referirem ao mesmo objeto deve ser dada prioridade à norma mais específica. $\mathrm{O}$ princípio pode ser aplicado em diversos contextos, desde entre dispositivos de um mesmo tratado, passando por conflitos entre dispositivos de tratados diversos e chegando a orientar a resolução de conflitos entre tratados e normas decorrentes de outras fontes ou entre dois parâmetros normativos não baseados em convenções. $A$ fonte, seja ela tratado, costume ou princípio geral não é um fator decisivo na determinação de qual é a norma mais específica, no entanto, a prática revela que tratados têm sido considerados como norma especial em relação a costumes e princípios gerais relativos ao mesmo assunto (ILC, 2006, p. 408-409).

O que se percebe é que os tratados são considerados uma fonte mais segura, ou que permite mais fácil determinação do conteúdo das obrigações internacionais, embora não possuam uma precedência ontológica sobre outras fontes, isto é, não existe hierarquia entre normas costumeiras e normas convencionais. Um tratado pode derrogar norma costumeira e vice-versa. Quanto ao relacionamento entre estas fontes, o que existe é uma maior operacionalidade dos tratados em relação aos costumes, visto que os primeiros oferecem maior facilidade para apuração de sua existência, do início de sua vigência, da determinação das № 40|p. $184-229$ | AGO - OUT 2013 
partes por eles obrigadas e do próprio conteúdo da norma a partir de seu texto. A definição da existência, vigência, sujeitos e teor das obrigações costumeiras é uma tarefa mais difícil, por conta disso é que as Nações Unidas têm como uma de suas tarefas a realização de estudos com vistas à progressiva sistematização e codificação do direito internacional, buscando consolidar, a partir da prática internacional, os costumes sob a forma de normas escritas (REZEK, 2011, p. 154155).

Deve-se ressaltar a diversidade de hipóteses de aplicação da máxima lex specialis, que pode resolver conflitos na aplicação de normas dentro de um mesmo tratado, ou entre tratados diferentes, ou entre normas oriundas de fontes diversas. A quinta conclusão não chega a detalhar a aplicação do preceito às soft norms (VARELLA, 2011, p. 81-85), no entanto, não parece haver nenhum obstáculo incontornável para isso, desde que se compreenda que os preceitos de hard law e as soft norms pertencem a categorias distintas. Feita esta ressalva, é possível imaginar a aplicação da máxima entre postulados do mesmo nível, isto é, entre dois ou mais preceitos de hard law ou entre duas ou mais soft norms. Da mesma forma, é possível que um postulado suave, não obrigatório, seja de auxílio no esclarecimento do sentido de um preceito jurídico internacional, desde que não implique alteração do sentido do mesmo.

As conclusões também procuram fazer notar que as relações entre a máxima lex specialis e outras normas de solução de conflitos, como a lex posteriori, não podem ser definidas em abstrato, devendo a determinação do preceito a prevalecer em cada caso ser realizada tendo em conta as circunstâncias do caso em análise (ILC, 2006, p. 409).

A determinação de tais circunstâncias vai envolver a situação fática, seus antecedentes, a vontade das partes envolvidas e o restante do direito aplicável. Como se vê, essa conclusão reforça o princípio da harmonização, pois a interpretação e aplicação do direito internacional deve sempre considerar a inserção da norma ou regime no contexto do direito internacional e este por sua vez deve ser considerado em conjunto com os fatores que lhe dão origem ou the modificam.

É evidente que a determinação da norma mais específica nem sempre será clara e evidente, mas isso é comum e somente pode ser resolvido no caso concreto e controlado por meio da obrigação que tem o magistrado de justificar sua REVISTA DO DIREITO UNISC, SANTA CRUZ DO SUL № 40| p. $184-229$ | AGO - OUT 2013 
preferência pela aplicação de certa norma entre as possíveis (MATHESON, 2007, p. 427).

Na sétima conclusão justifica-se a prioridade da norma mais específica por sua maior proximidade e adequação aos fatos que regula, normalmente oferecendo resultados mais equitativos e concordes à vontade das partes. A lei especial tem prioridade de aplicação em relação à lei geral por ser mais concreta e melhor considerar as características particulares do contexto fático em que será aplicada, do mesmo modo, sua aplicação permite, com maior frequência, oferecer um resultado mais justo e que melhor reflita as intenções das partes contratantes (ILC, 2006, p. 409).

O direito geral fornece as linhas mestras, mas, por sua característica essencial, de prover um plano de fundo para a aplicação das normas às situações concretas, não tem o grau de detalhamento que frequentemente é necessário à segurança e previsibilidade das relações internacionais. Por outro lado, as normas gerais são indispensáveis para vincular normas, tratados e conjuntos de tratados vinculados a determinado assunto à estrutura mais abrangente do direito internacional, bem como para delinear as características distintivas dessa ordem jurídica. Esse tem sido um dos desafios decorrentes do fenômeno de expansão e diversificação do direito internacional, a manutenção da unidade em meio à diversidade, principalmente em um contexto político-jurídico no qual os Estados procuram promover suas agendas por meio do adensamento normativo dos subsistemas jurídicos que melhor refletem seus interesses. O pleito por maior autonomia para esses subsistemas é, neste contexto, compreensível. No entanto, longe de representar um risco de fragmentação, tais pleitos revelam a existência de um quadro normativo mais amplo, cujas exigências jurídicas nem sempre agradam ou são expedientes, mas que pautam a evolução do direito internacional.

Por outro lado, o direito internacional permanece um sistema dotado de elasticidade suficiente para conviver com evoluções e modificações constantes sem perder sua integralidade. É disso que fala a oitava conclusão, ao mencionar as funções do preceito lei especial revoga lei geral, pois a maior parte do direito internacional é dispositiva e isso significa que normas específicas podem ser utilizadas em benefício da melhor aplicação ou da clareza, bem como para atualizar, modificar ou mesmo afastar o direito geral (ILC, 2006, p. 409). 
Efetivamente, a maior parte do direito internacional é dispositivo, ou seja, na maioria das vezes, suas alterações estão condicionadas unicamente à observância do princípio pacta sunt servanda, com isso, normas mais específicas podem esclarecer, modificar ou afastar o direito geral. Por conta dessa característica, as mudanças no direito internacional com o surgimento de novas áreas temáticas de regulação não representam o fim do direito internacional, ao contrário, remetem à crescente necessidade dos atores internacionais de terem as suas relações estabilizadas pelo direito.

As normas gerais e as normas específicas compõem o quadro de necessária diversidade normativa que permite ao direito internacional adaptar-se às novas necessidades da sociedade internacional ao mesmo tempo em que preserva suas características essenciais. É o que reza a nona conclusão, na qual a Comissão de Direito Internacional afirma que a aplicação da lei especial, via de regra, não extingue a lei geral que continuará, de acordo com o princípio da harmonização, exposto na quarta conclusão, a orientar a interpretação e aplicação da lei especial, permanecendo plenamente aplicável nas situações não previstas por esta (ILC, 2006, p. 409).

Assim sendo, a aplicação do preceito lex specialis não acarreta a revogação do direito geral, mas apenas afasta sua aplicação naquele caso específico - o direito geral permanece fornecendo o contexto de aplicação do direito e aplica-se a todos os pontos para os quais a norma especial não prover solução (MATHESON, 2007, p. 427).

É claro que surge certa inquietação quanto ao papel crescentemente subsidiário do direito internacional geral. Pode-se mesmo indagar se não será essa subsidiariedade que acabará por tornar os subsistemas jurídicos específicos ilhas desconectadas em meio à regulação incoerente e conflitante. Esse momento, no entanto, ainda não chegou. Ao contrário, certos segmentos do direito internacional geral seguem, sólidos, como os pilares normativos do sistema, sujeitos à evolução, evidentemente, mas indispensáveis para regular as relações entre os atores internacionais. Pode-se citar como exemplos o direito que regula as relações diplomáticas e consulares, a responsabilidade internacional e o direito dos tratados.

Sobre essa questão da permanência e transitoriedade das normas no direito internacional, Paul Guggenheim deu, em seu curso na Academia de Direito REVISTA DO DIREITO UNISC, SANTA CRUZ DO SUL № 40| p. $184-229$ | AGO - OUT 2013 
Internacional, há mais de cinquenta anos, uma importante contribuição. Segundo ele, a origem histórica de um grande número de normas internacionais está ligada ao sistema criado pela Paz de Westphalia (1648), estando intimamente relacionadas ao Estado moderno. De acordo com a evolução histórica dessas normas é possível dividi-las entre aquelas que pouco se modificaram após sua criação e revelam a presença de uma estrutura que se modifica muito lentamente e que encontrou expressão no moderno sistema de Estados, aquelas que se modificaram em função de mudanças políticas e econômicas, mas que conservaram algumas características intrínsecas e aquelas que surgiram por razões passageiras, tiveram sua importância e depois caíram em desuso (GUGGENHEIM, 1952, p. 49-50).

Da categoria das normas mais estáveis e estruturais do sistema jurídico internacional progressivamente chegou-se à concepção de jus cogens, normas internacionais peremptórias que só podem ser alteradas por outra norma da mesma natureza, na conformação dada pelo art. 53 da Convenção de Viena sobre Direito dos Tratados. Tão fundamentais são essas normas que não podem ser afastadas por outras mais específicas. É o que reza, entre outras coisas, a décima conclusão do Grupo de Estudos sobre a fragmentação, ao tratar dos tipos de direito geral que não podem ser derrogados por via de norma especial. A décima conclusão refere-se expressamente ao jus cogens como uma categoria de normas não derrogáveis por outras mais específicas e vai além, apresentando critérios que justificam a prevalência do direito internacional geral em face de normas mais específicas. Nestes casos, a presunção contida no preceito lex specialis não se aplica, seja porque a prevalência do direito geral pode ser inferida de sua forma ou de sua natureza, ou então do propósito das partes obrigadas pelas normas em consideração. Do mesmo modo, a norma mais específica não é aplicável quando isto frustrar o propósito da lei geral, o que significa que, em cada caso, o aplicador do direito deve enfrentar a difícil tarefa de considerar o quanto estas últimas podem ser afastadas ou modificadas em face das primeiras. Outro aspecto que pode tornar a lei especial inaplicável é o impacto de sua aplicação em relação a terceiros, momento em que se deve considerar o potencial impacto negativo de novas obrigações, assumidas entre partes diferentes, em relação a obrigações anteriores mais abrangentes ou assumidas com outras partes. Finalmente, deve ser considerado o equilíbrio de direitos e obrigações definido pelo direito internacional № 40| p. $184-229$ | AGO - OUT 2013 
geral e avaliar o quanto este equilíbrio pode ser prejudicado pela aplicação de normas mais específicas (ILC, 2006, p. 410).

Como visto, a máxima lex specialis também pode ter sua aplicação afastada em decorrência da natureza ou forma da norma geral em questão, da vontade das partes, ou caso a aplicação da norma especial possa frustrar o propósito da norma geral, gerar prejuízos a terceiros ou comprometer o equilíbrio das relações jurídicas.

Em síntese, há casos em que as normas especiais não irão prevalecer em relação às normas gerais, tal é o caso quando a norma geral for imperativa, ou quando o contexto, a intenção das partes envolvidas, ou o equilíbrio das obrigações implicarem em tal solução (MATHESON, 2007, p. 427).

\subsection{Regimes especiais (self contained regimes)}

Também, o preceito lex specialis também se aplica a conjuntos normativos vigentes em determinadas regiões ou relativas a certos assuntos, embora neste último caso, quando ocorre um conflito entre dois regimes especializados seja difícil determinar qual é o geral e qual é o específico. De todo modo, nenhum subsistema jurídico existe isolado do direito internacional geral, que o situa dentro da moldura do sistema jurídico internacional como um todo e provê as regras básicas para seu funcionamento (MATHESON, 2007, p. 427-428).

Esses conjuntos normativos especiais, que são chamados nas conclusões de regimes especiais, são formados por regras e princípios que dizem respeito a um determinado assunto em particular. Eles podem formar um subsistema dotado de características próprias e que, em termos de aplicação, podem ser considerados como lex specialis. Como tal, esses subsistemas às vezes possuem instituições próprias que os administram (ILC, 2006, p. 410).

Nas conclusões, o Grupo de Estudos distinguiu três tipos de regimes especiais. O primeiro tipo é composto por aqueles que consistem num sistema peculiar de sanções relacionados à prática de violações de um certo conjunto de normas e que é o principal objeto das prescrições do artigo 55 da projetada Convenção sobre a Responsabilidade Internacional pela prática de atos ilícitos internacionais. O segundo grupo é constituído por conjuntos especiais de normas, № $40 \mid$ p. $184-229$ | AGO - OUT 2013 
contendo direitos e obrigações e relacionados a certo tema, acidente ou espaço geográfico específicos, que podem surgir a partir de um ou vários tratados e de sua conjugação com a prática subsequente à vigência daquele conjunto normativo e o direito costumeiro que pode daí decorrer. O terceiro gênero é caracterizado por regimes especiais decorrentes da agregação de conjuntos normativos em torno de problemas jurídicos específicos, agregados em torno de certa área, é o caso de expressões como direito do mar, ou direito humanitário, ou direito do comércio, que agregam em uma mesma área temática diversos instrumentos jurídicos e prática jurídica relativa à aplicação dos mesmos e os considera para efeitos hermenêuticos como um conjunto coerente (ILC, 2006, p. 411).

As conclusões do Grupo de Estudos indicam também o que significa em termos práticos a especificidade de um regime especial, esclarecendo que essa característica diz respeito à sua unidade em torno de um mesmo objeto ou problema e à elaboração de um subsistema que busca avançar um mesmo propósito. Em decorrência disso, a interpretação e aplicação desses subsistemas devem, na medida do possível, ater-se à sua área ou problema focal e manter a coerência com os propósitos que motivaram a construção daquele conjunto normativo especial (ILC, 2006, p. 411).

Com relação à interação entre os regimes especiais, mencionados acima, e o direito internacional geral, o Grupo de Estudos concluiu que os primeiros podem prevalecer sobre os últimos de acordo com os parâmetros estabelecidos para aplicação do preceito lex specialis (ILC, 2006, p. 412).

Da mesma forma, o direito internacional geral mantém o seu papel de fornecer um substrato coerente para o funcionamento dos regimes especiais, pois estes, possuindo um alcance mais restrito, apresentarão vez por outra lacunas às instituições encarregadas de sua aplicação, as quais terão de socorrer-se das normas gerais aplicáveis em cada circunstância para orientar a produção de decisões (ILC, 2006, p. 412).

Em determinadas circunstâncias, os regimes especiais e as instituições neles baseadas podem podem fracassar. Isso pode ocorrer em decorrência da incapacidade do conjunto normativo e das instituições criadas para efetivá-lo de fornecer soluções para as áreas e problemas em função dos quais foram constituídos, podendo acontecer de seus propósitos não serem alcançados, ou pela 
constante ausência de obediência às suas normas por parte das partes obrigadas, ou mesmo por desuso do subsistema, ou retirada de parte significativa de seus membros. Para determinar a ocorrência do fracasso do regime é necessário avaliar os seus instrumentos constitutivos para inferir o mínimo nível de efetividade que o regime deve apresentar para que não se configure alguma das formas possíveis de colapso do mesmo. Constatado o fracasso do subsistema, as normas do direito internacional geral aplicáveis reassumirão o seu papel na regência da matéria (ILC, 2006, p. 412).

\subsection{Artigo 31(3)(c) da Convenção de Viena sobre Direito dos Tratados (CVDT)}

No relatório analítico, o art. $31(3)(c)$ da CVDT foi tratado no item F (KOSKENNIEMI, 2006, p. 206-243).

O artigo 31.3.c da CVDT é um dos dispositivos deste diploma que orienta como devem ser consideradas as relações de interpretação, estipulando que o intérprete de um tratado deve levar em conta quaisquer normas relevantes do direito internacional aplicáveis às relações entre as partes envolvidas, no momento de resolver alguma disputa acerca de suas obrigações recíprocas. Esta conclusão apresenta ao jurista a meta de integrar de forma sistêmica as diversas obrigações internacionais, procurando sempre, diante de um suposto conflito, elaborar a construção hermenêutica mais apta a dar cumprimento ao conjunto das obrigações nas quais estão envolvidas as partes, pois, quaisquer que seja o objeto de tais obrigações, elas foram originadas no sistema jurídico internacional e devem ser consideradas como partes dele integrantes, de modo a constituir um todo coerente (ILC, 2006, p. 413).

Por conta disso, a interpretação das obrigações internacionais deve ser vista também como integração dessas obrigações em um sistema mais amplo. Assim, o princípio da integração sistêmica deve governar toda a interpretação dos tratados, sendo que os outros aspectos de relevo na atividade hermenêutica estão regulados nos artigos 31 e 32 da CVDT, os quais descrevem um processo de argumentação jurídica no qual elementos particulares irão adquirir maior ou menos relevância de acordo com a natureza das disposições do tratado consideradas no contexto de sua interpretação e aplicação. Em muitos casos, a interpretação de um tratado poderá ser realizada dentro de sua própria sistemática, o artigo 31.3.c aplica- 
se às situações nas quais a definição do alcance dos dispositivos de um tratado dependerá de fontes externas, que serão relevantes para sua interpretação, estas poderão incluir outros tratados, costumes e princípios gerais de direito (ILC, 2006, p. 413).

Na mesma linha segue a décima nona conclusão, afirmando:

(19) Application of systemic integration. Where a treaty functions in the context of other agreements, the objective of systemic integration will apply as a presumption with both positive and negative aspects:

(a) The parties are taken to refer to customary international law and general principles of law for all questions which the treaty does not itself resolve in express terms;

(b) In entering into treaty obligations, the parties do not intend to act inconsistently with generally recognized principles of international law. Of course, if any other result is indicated by ordinary methods of treaty interpretation that should be given effect, unless the relevant principle were part of jus cogens (ILC, 2006, p. 413-414).

Diz ainda a vigésima conclusão:

(20) Application of custom and general principles of law. Customary international law and general principles of law are of particular relevance to the interpretation of a treaty under article 31 (3) (c) especially where:

(a) The treaty rule is unclear or open-textured;

(b) The terms used in the treaty have a recognized meaning in customary international law or under general principles of law;

(c) The treaty is silent on the applicable law and it is necessary for the interpreter, applying the presumption in conclusion (19) (a) above, to look for rules developed in another part of international law to resolve the point (ILC, 2006, p. 414).

Esmiuçando a aplicação do dispositivo ter-se-á a vigésima primeira conclusão:

(21) Application of other treaty rules. Article 31 (3) (c) also requires the interpreter to consider other treaty-based rules so as to arrive at a consistent meaning. Such other rules are of particular relevance where parties to the treaty under interpretation are also parties to the other treaty, where the treaty rule has passed into or expresses customary. international law or where they provide evidence of the common understanding of the parties as to the object and purpose of the treaty under interpretation or as to the meaning of a particular term (ILC, 2006, p. 414-415). 
Quanto à consideração dos efeitos temporais na interpretação sistêmica, orienta a vigésima segunda conclusão:

(22) Inter-temporality. International law is a dynamic legal system. A treaty may convey whether in applying article 31 (3) (c) the interpreter should refer only to rules of international law in force at the time of the conclusion of the treaty or may also take into account subsequent changes in the law. Moreover, the meaning of a treaty provision may also be affected by subsequent developments, especially where there are subsequent developments in customary law and general principles of law (ILC, 2006, p. 415).

A vigésima terceira conclusão acrescenta orientação relativa aos conceitos abertos ou sujeitos à modificação:

(23) Open or evolving concepts. Rules of international law subsequent to the treaty to be interpreted may be taken into account especially where the concepts used in the treaty are open or evolving. This is the case, in particular, where: (a) the concept is one which implies taking into account subsequent technical, economic or legal developments; (b) the concept sets up an obligation for further progressive development for the parties; or (c) the concept has a very general nature or is expressed in such general terms that it must take into account changing circumstances (ILC, 2006, p. 415416).

Sintetizando o acima exposto, Matheson assinala que as conclusões tratam do tema da interpretação de tratados, considerando o artigo 31(3)(c) da Convenção de Viena sobre Direito dos Tratados, que determina que seja levado em conta na interpretação de um tratado as regras relevantes do direito internacional aplicáveis às relações entre as partes. O Grupo de Estudos designou este dispositivo de princípio da integração sistêmica, à luz do qual os tratados devem ser interpretados como integrantes do sistema geral do direito internacional e não de forma isolada. Daí afirmar-se nas conclusões que as partes devem referir-se ao direito internacional costumeiro e aos princípios gerais de direito para solução de todas as questões que não forem explicitamente resolvidas no corpo do tratado. Além disso, do princípio da integração sistêmica presume-se que nenhum Estado contrai uma obrigação que seja incoerente com as normas gerais do direito internacional ou flagrantemente incompatível com suas obrigações anteriores (MATHESON, 2007, p. 428). 


\subsection{Conflitos entre normas sucessivas}

No relatório analítico, o conflito entre normas sucessivas foi tratado no item D, intitulado "Conflito entre normas sucessivas - art. 30 CVDT - cláusulas especiais e acordos inter se" (KOSKENNIEMI, 2006, p. 115-165).

Diz o artigo 30:

Artigo 30 - Aplicação de Tratados Sucessivos sobre o Mesmo Assunto

1. Sem prejuízo das disposições do artigo 103 da Carta das Nações Unidas, os direitos e obrigações dos Estados partes em tratados sucessivos sobre 0 mesmo assunto serão determinados de conformidade com os parágrafos seguintes.

2. Quando um tratado estipular que está subordinado a um tratado anterior ou posterior ou que não deve ser considerado incompatível com esse outro tratado, as disposições deste último prevalecerão.

3. Quando todas as partes no tratado anterior são igualmente partes no tratado posterior, sem que o tratado anterior tenha cessado de vigorar ou sem que a sua aplicação tenha sido suspensa nos termos do artigo 59, o tratado anterior só se aplica na medida em que as suas disposições sejam compatíveis com as do tratado posterior.

4. Quando as partes no tratado posterior não incluírem todas as partes no tratado anterior:

a) nas relações entre os Estados partes nos dois tratados, aplica-se o disposto no parágrafo 3;

b) nas relações entre um Estado parte nos dois tratados e um Estado parte apenas em um desses tratados, o tratado em que os dois Estados são partes rege os seus direitos e obrigações recíprocas.

5. O parágrafo 4 aplica-se sem prejuízo do artigo 41 , ou de qualquer questão relativa à extinção ou suspensão da execução de um tratado nos termos do artigo 60 ou de qualquer questão de responsabilidade que possa surgir para um Estado da conclusão ou da aplicação de um tratado cujas disposições sejam incompatíveis com suas obrigações em relação a outro Estado nos termos de outro tratado.

A vigésima quarta conclusão enuncia o preceito lex posteriori derogat priori, em conformidade com o art. 30 da CVDT:

(24) Lex posterior derogat legi priori. According to article 30 VCLT, when all the parties to a treaty are also parties to an earlier treaty on the same subject, and the earlier treaty is not suspended or terminated, then it applies only to the extent its provisions are compatible with those of the later treaty.

REVISTA DO DIREITO UNISC, SANTA CRUZ DO SUL № $40 \mid$ p. $184-229$ | AGO - OUT 2013 
This is an expression of the principle according to which "later law supersedes earlier law" (ILC, 2006, p. 416).

Nas conclusões consta a aplicação na máxima lex posteriori, que também não é um preceito absoluto, pois não se aplica quando as partes envolvidas tenham resolvido em sentido contrário. Ele atua de maneira mais intensa quando se trata de sucessão de tratados em matérias correlatas. Do mesmo modo, o princípio não se aplica quando as partes de um conjunto posterior de obrigações não são as mesmas de um conjunto anterior (MATHESON, 2007, p. 428).

As limitações ao princípio de sucessão temporal são elucidadas na orientação contida na vigésima quinta conclusão:

(25) Limits of the "lex posterior" principle. The applicability of the lex posterior principle is, however, limited. It cannot, for example, be automatically extended to the case where the parties to the subsequent treaty are not identical to the parties of the earlier treaty. In such cases, as provided in article 30 (4) VCLT, the State that is party to two incompatible treaties is bound vis-à-vis both of its treaty parties separately. In case it cannot fulfil its obligations under both treaties, it risks being responsible for the breach of one of them unless the concerned parties agree otherwise. In such case, also article 60 VCLT may become applicable. The question which of the incompatible treaties should be implemented and the breach of which should attract State responsibility cannot be answered by a general rule. Conclusions (26)-(27) below lay out considerations that might then be taken into account (ILC, 2006, p. 416-417).

A vigésima sexta conclusão orienta quanto à distinção entre dispositivos de tratados que pertencem ao mesmo regime e as disposições que pertencem a regimes diferentes:

(26) The distinction between treaty provisions that belong to the same "regime" and provisions in different "regimes". The lex posterior principle is at its strongest in regard to conflicting or overlapping provisions that are part of treaties that are institutionally linked or otherwise intended to advance similar objectives (i.e. form part of the same regime). In case of conflicts or overlaps between treaties in different regimes, the question of which of them is later in time would not necessarily express any presumption of priority between them. Instead, States bound by the treaty obligations should try to implement them as far as possible with the view of mutual accommodation and in accordance with the principle of harmonization. However, the 
substantive rights of treaty parties or third party beneficiaries should not be undermined (ILC, 2006, p. 417).

Já a vigésima sétima conclusão faz referência aos diferentes tipos de tratados e de dispositivos contidos em tratados:

(27) Particular types of treaties or treaty provisions. The lex posterior presumption may not apply where the parties have intended otherwise, which may be inferred from the nature of the provisions or the relevant instruments, or from their object and purpose. The limitations that apply in respect of the lex specialis presumption in conclusion (10) may also be relevant with respect to the lex posterior (ILC, 2006, p. 417).

Quando da ocorrência de conflitos entre regimes jurídicos distintos e sua solução, o Grupo de Estudos propôs a seguinte conclusão:

(28) Settlement of disputes within and across regimes. Disputes between States involving conflicting treaty provisions should be normally resolved by negotiation between parties to the relevant treaties. However, when no negotiated solution is available, recourse ought to be had, where appropriate, to other available means of dispute settlement. When the conflict concerns provisions within a single regime (as defined in conclusion (26) above), then its resolution may be appropriate in the regime-specific mechanism. However, when the conflict concerns provisions in treaties that are not part of the same regime, special attention should be given to the independence of the means of settlement chosen (ILC, 2006, p. 417-418).

\section{A vigésima nona conclusão diz respeito aos acordos inter se:}

(29) Inter se agreements. The case of agreements to modify multilateral treaties by certain of the parties only (inter se agreements) is covered by article 41 VCLT. Such agreements are an often used technique for the more effective implementation of the original treaty between a limited number of treaty parties that are willing to take more effective or more far-reaching measures for the realization of the object and purpose of the original treaty. Inter se agreements may be concluded if this is provided for by the original treaty or it is not specifically prohibited and the agreement: "(i) does not affect the enjoyment by the other parties of their rights under the treaty or the performance of their obligations; (ii) does not relate to a provision, derogation from which is incompatible with the effective execution of the object and purpose of the treaty as a whole" (article 41 (1) (b) VCLT) (ILC, 2006, p. 418).

Como se vê, a orientação é condizente com o teor do art. 41 da CVDT, verbis: 
Artigo 41

Acordos para Modificar Tratados Multilaterais somente entre Algumas Partes

1. Duas ou mais partes num tratado multilateral podem concluir um acordo para modificar o tratado, somente entre si, desde que:

a) a possibilidade de tal modificação seja prevista no tratado; ou

b) a modificação em questão não seja proibida pelo tratado; e

i) não prejudique o gozo pelas outras partes dos direitos provenientes do tratado nem o cumprimento de suas obrigações

ii) não diga respeito a uma disposição cuja derrogação seja incompatível com a execução efetiva do objeto e da finalidade do tratado em seu conjunto.

2. A não ser que, no caso previsto na alínea a do parágrafo 1 , o tratado disponha de outra forma, as partes em questão notificarão às outras partes sua intenção de concluir o acordo e as modificações que este introduz no tratado.

Na trigésima conclusão, o Grupo de estudos abordou a questão dos conflitos entre cláusulas de tratados distintos e da necessidade de preservar os direitos de terceiros:

(30) Conflict clauses. When States enter into a treaty that might conflict with other treaties, they should aim to settle the relationship between such treaties by adopting appropriate conflict clauses. When adopting such clauses, it should be borne in mind that:

(a) They may not affect the rights of third parties;

(b) They should be as clear and specific as possible. In particular, they should be directed to specific provisions of the treaty and they should not undermine the object and purpose of the treaty;

(c) They should, as appropriate, be linked with means of dispute settlement (ILC, 2006, p. 418).

Assim, a Comissão ofereceu uma série de orientações, sob a forma de conclusões, acerca da sucessão de normas no tempo, privilegiando a aplicação extensiva da CVDT à matéria.

\subsection{Hierarquia no direito internacional}


No relatório analítico, o tema da hierarquia das normas foi tratado no item E, intitulado "Relações de importância - art. 103 da Carta, jus cogens, obrigações erga omnes como regras de conflito" (KOSKENNIEMI, 2006, p. 166-205).

Segundo Matheson, o assunto mais controvertido sobre o qual versaram as conclusões é o da hierarquia relativa dos diferentes tipos de normas jurídicas internacionais. Os membros do Grupo concordaram que não existe hierarquia entre as principais fontes do direito internacional, a saber: costumes, tratados e princípios gerais reconhecidos por todos os sistemas jurídicos. No entanto, significativo debate foi travado acerca de três outras categorias, cuja relevância hierárquica foi discutida: jus cogens, o artigo 103 da Carta das Nações Unidas e as obrigações erga omnes (MATHESON, 2007, p. 424).

Quanto ao espinhoso tema da hierarquia das normas no direito internacional, o Grupo de Estudos propôs, em sua trigésima primeira conclusão:

(31) Hierarchical relations between norms of international law. The main sources of international law (treaties, custom, general principles of law as laid out in Article 38 of the Statute of the International Court of Justice) are not in a hierarchical relationship inter se. Drawing analogies from the hierarchical nature of domestic legal system is not generally appropriate owing to the differences between the two systems. Nevertheless, some rules of international law are more important than other rules and for this reason enjoy a superior position or special status in the international legal system. This is sometimes expressed by the designation of some norms as "fundamental" or as expressive of "elementary considerations of humanity" or "intransgressible principles of international law". What effect such designations may have is usually determined by the relevant context or instrument in which that designation appears (ILC, 2006, p. 418-419).

A ideia de jus cogens já fora consagrada no artigo 53 da Convenção de Viena sobre Direito dos Tratados, que dispõe que um tratado é nulo se conflitar com uma norma peremptória de direito internacional geral. Tais normas são aquelas aceitas pela comunidade internacional como um todo e das quais nenhuma derrogação é possível, a não ser por outra norma de mesmo nível. Daí decorreria a superioridade das normas de ius cogens. Alguns membros do Grupo de Estudos procuraram ampliar a lista dessas normas, particularmente no campo dos direitos humanos, entretanto, o Grupo percebeu que a negociação da composição de tal lista não era viável nem desejável, apontando, no entanto, os exemplos mais citados de 
tais normas: proibição à escravidão, ao tráfico de escravos, ao genocídio, à discriminação racial, ao apartheid, aos crimes contra a humanidade e à tortura, bem como o direito à autodeterminação. Não existe um rol taxativo e acabado de jus cogens, tanto que os exemplos citados no relatório analítico, finalizado pelo presidente do Grupo, são mais numerosos, incluindo o direito à legítima defesa (selfdefense), a proibição da pirataria e a proibição de hostilidades dirigidas contra a população civil. Da mesma forma, novos direitos dessa natureza podem surgir à partir do reconhecimento e aceitação dos mesmos pelo conjunto da comunidade internacional (MATHESON, 2007, p. 424).

Sobre jus cogens, diz a trigésima segunda conclusão:

(32) Recognized hierarchical relations by the substance of the rules: Jus cogens. A rule of international law may be superior to other rules on account of the importance of its content as well as the universal acceptance of its superiority. This is the case of peremptory norms of international law (jus cogens, Article 53 VCLT), that is, norms "accepted and recognized by the international community of States as a whole from which no derogation is permitted" (ILC, 2006, p. 419).

Em relação ao conteúdo do jus cogens, assim se manifestou o Grupo de Estudos:

(33) The content of jus cogens. The most frequently cited examples of jus cogens norms are the prohibition of aggression, slavery and the slave trade, genocide, racial discrimination apartheid and torture, as well as basic rules of international humanitarian law applicable in armed conflict, and the right to self-determination. Also other rules may have a jus cogens character inasmuch as they are accepted and recognized by the international community of States as a whole as norms from which no derogation is permitted (ILC, 2006, p. 419-420).

O Grupo ressaltou a importância hierárquica do artigo 103 da Carta das Nações Unidas, que prevê a prevalência das obrigações dos Estados constantes na Carta diante de outras obrigações internacionais. Leia-se a trigésima quarta conclusão:

(34) Recognized hierarchical relations by virtue of a treaty provision: Article 103 of the Charter of the United Nations. A rule of international law may also be superior to other rules by virtue of a treaty provision. This is the case of Article 103 of the United Nations Charter by virtue of which "In the event of a conflict between the obligations of the Members of the United Nations under 
the ... Charter and their obligations under any other international agreement, their obligations under the ... Charter shall prevail" (ILC, 2006, p. 420).

O Grupo de Estudos também incluiu as obrigações decorrentes de órgãos como o Conselho de segurança. Tal prevalência, na perspectiva exposta nas conclusões, se apresentaria também em relação a direito internacional costumeiro que se revelasse inconsistente (MATHESON, 2007, p. 424-425).

Sobre isso, pode-se ler a trigésima quinta conclusão:

(35) The scope of Article 103 of the Charter. The scope of Article 103 extends not only to the Articles of the Charter but also to binding decisions made by United Nations organs such as the Security Council. Given the character of some Charter provisions, the constitutional character of the Charter and the established practice of States and United Nations organs, Charter obligations may also prevail over inconsistent customary international law (ILC, 2006, p. 420).

Sobre a posição da Carta das Unidas em um contexto de hierarquização do Direito Internacional, a trigésima sexta conclusão afirma:

(36) The status of the United Nations Charter. It is also recognized that the United Nations Charter itself enjoys special character owing to the fundamental nature of some of its norms, particularly its principles and purposes and its universal acceptance (ILC, 2006, p. 420).

Com relação às obrigações erga omnes, estas são definidas na trigésima sétima conclusão:

(37) Rules specifying obligations owed to the international community as a whole: Obligations erga omnes. Some obligations enjoy a special status owing to the universal scope of their applicability. This is the case of obligations erga omnes, that is obligations of a State towards the international community as a whole. These rules concern all States and all States can be held to have a legal interest in the protection of the rights involved. Every State may invoke the responsibility of the State violating such obligations (ILC, 2006, p. 420-421).

A conclusão seguinte elucida a relação entre as obrigações erga omnes e o jus cogens:

(38) The relationship between jus cogens norms and obligations erga omnes. It is recognized that while all obligations established by jus cogens norms, as referred to in conclusion (33) above, also have the character of erga omnes obligations, the reverse is not necessarily true. Not all erga omnes obligations are established by peremptory norms of general 
international law. This is the case, for example, of certain obligations under "the principles and rules concerning the basic rights of the human person", as well as of some obligations relating to the global commons (ILC, 2006, p. 421).

O conceito de obrigações erga omnes adotado foi o de obrigações dos Estados em relação à comunidade internacional como um todo. Como tal, não traduz um preceito hierárquico, mas sim a identificação de certas obrigações devidas ao conjunto dos membros do sistema internacional. Também nesse caso o Grupo de Estudos se absteve de tentar formular uma lista dessa espécie de obrigações (MATHESON, 2007, p. 425).

Refletindo as dificuldades para circunscrever o conceito de obrigações erga omnes, o Grupo de Estudos concluiu:

(39) Different approaches to the concept of obligations erga omnes. The concept of erga omnes obligations has also been used to refer to treaty obligations that a State owes to all other States parties (obligations erga omnes partes) or to non-party States as third party beneficiaries. In addition, issues of territorial status have frequently been addressed in erga omnes terms, referring to their opposability to all States. Thus, boundary and territorial treaties have been stated to "represent[] a legal reality which necessarily impinges upon third States, because they have effect erga omnes" (ILC, 2006, p. 422).

Para Matheson, o aspecto mais interessante da discussão sobre hierarquia foi a questão das relações entre os três tipos de obrigações acima mencionadas. O Grupo firmou que jus cogens e obrigações erga omnes são coisas diferentes. Todas as normas de jus cogens tem o caráter de obrigações erga omnes. Mas o contrário não se verifica. Com relação ao suposto conflito entre normas de jus cogens e obrigações decorrentes do artigo 103 da Carta, o relatório analítico opinou pela prevalência das primeiras (MATHESON, 2007, p. 425).

Em suas conclusões, o Grupo de Estudos foi cauteloso ao definir as relações entre jus cogens e as obrigações constantes na Carta das Nações Unidas, como se vê na quadragésima conclusão:

(40) The relationship between jus cogens and the obligations under the United Nations Charter. The United Nations Charter has been universally accepted by States and thus a conflict between jus cogens norms and Charter obligations is difficult to contemplate. In any case, according to Article 24 (2) of the Charter, the Security Council shall act in accordance REVISTA DO DIREITO UNISC, SANTA CRUZ DO SUL № 40| p. $184-229$ | AGO - OUT 2013 
with the Purposes and Principles of the United Nations which include norms that have been subsequently treated as jus cogens (ILC, 2006, p. 422).

Quanto às relações entre jus cogens e o artigo 103, diz a quadragésima primeira conclusão:

(41) The operation and effect of jus cogens norms and Article 103 of the Charter:

(a) A rule conflicting with a norm of jus cogens becomes thereby ipso facto void;

(b) A rule conflicting with Article 103 of the United Nations Charter becomes inapplicable as a result of such conflict and to the extent of such conflict (ILC, 2006, p. 423).

A última conclusão do estudo refere-se à relação entre hierarquia e o princípio da harmonização:

(42) Hierarchy and the principle of harmonization. Conflicts between rules of international law should be resolved in accordance with the principle of harmonization, as laid out in conclusion (4) above. In the case of conflict between one of the hierarchically superior norms referred to in this section and another norm of international law, the latter should, to the extent possible, be interpreted in a manner consistent with the former. In case this is not possible, the superior norm will prevail (ILC, 2006, p. 423).

Embora concorde com o teor das conclusões, Matheson ressalta que estas devem ser lidas em conjunto com o relatório analítico (ILC, 2006, p. 402), e comenta:

In my view, this is a correct - if not entirely definitive - summary of the situation. By definition, jus cogens norms are only created by the universal acceptance of the international community of states, and it is therefore difficult to see how any jus cogens norm could have developed that would be inconsistent with the UN Charter -which also has been universally accepted by states. This acceptance includes the responsibility and authority given to the Security Council to make binding decisions under Chapter VII of the Charter. Thus, jus cogens norms must be interpreted in a way that is consistent with the Council's authority under the Charter: for example, the prohibition on aggression should not be interpreted to preclude the authorization by the Council of non defensive force; and the principle of selfdetermination - if indeed it is jus cogens - should not be interpreted to preclude decisions by the Council on the status of particular territories that are designed to preserve the peace but might otherwise be thought to infringe on sovereignty or self-determination (MATHESON, 2007, p. 426).

REVISTA DO DIREITO UNISC, SANTA CRUZ DO SUL № $40 \mid$ p. $184-229$ | AGO - OUT 2013 
De acordo com Koskenniemi, a Convenção de Viena sobre Direito dos Tratados fornece a base jurídica para desenvolvimento de um direito internacional dos conflitos. A ideia é que técnicas similares as que já são empregadas no âmbito do direito internacional privado para definir a jurisdição competente e a legislação aplicável podem ser também empregadas, com as devidas adaptações, para determinar qual tribunal internacional poderá julgar um caso e qual direito deverá ser aplicado (KOSKENNIEMI, 2006, p. 244-249).

Koskenniemi ressalta que a resolução de conflitos não pode obedecer à lógica interna de nenhum sistema normativo específico, pois haveria nestes uma tendência a privilegiar o tratamento de certas matérias - o desenvolvimento das técnicas de resolução de conflitos entre diversos sistemas normativos de direito internacional caberia, portanto, ao direito internacional geral, tendo por base o direito dos tratados e a Convenção de Viena (KOSKENNIEMI, 2006, p. 250-256).

Regimes são conjuntos de normas com variado grau de cogência e aproximados por afinidade temática, sem relação hierárquica entre si. A concepção de regime é mais ampla que a de ordem jurídica, pois permite incluir todas as normas que surgiram após a Segunda Guerra Mundial e que traduzem normativamente não apenas comandos peremptórios, mas também programas de ação e valores.

Matheson faz notar ainda que o estudo sobre a fragmentação não se debruçou sobre seus aspectos institucionais, a exemplo da proliferação de instâncias jurisdicionais com competências sobrepostas, afastando-se da delicada questão sobre o grau em que os tribunais internacionais são vinculados aos pronunciamentos da Corte Internacional de Justiça (MATHESON, 2007, p. 429).

\section{REPERCUSSÃO DOS TRABALHOS DO GRUPO DE ESTUDOS}

O fenômeno da fragmentação pode ser encarado como uma consequência da expansão do próprio direito internacional. À medida que este passou a assumir um papel regulador mais amplo e pronunciado das relações entre os Estados, foi necessária uma especialização temática para atender às peculiaridades de vários segmentos e essa necessidade acentuou-se a partir da II Guerra Mundial. 
Para Koskenniemi, essa especialização é parte de um processo mais abrangente de diferenciação funcional e ocorre juntamente com uma relativa ignorância entre os diversos sistemas normativos que se formam (KOSKENNIEMI, 2006, p. 11).

É possível supor que o próprio processo de diferenciação funcional gera especialização e relativa desinteligência entre os subsistemas do direito internacional, para não falar de aberta competição entre os mesmos pelo predomínio no campo regulatório. Isso pode de fato ser visto como uma ameaça, pois conduz à dissolução da ideia de ordem jurídica, de coerência e de unidade, tão caras aos juristas.

No entanto, essas preocupações parecem assumir o falso pressuposto de que o direito internacional tenha em algum momento sido um corpo homogêneo e estruturado de normas e que, em determinado momento, tenha se quebrado. $\mathrm{Na}$ verdade, o direito internacional sempre foi um conjunto dinâmico de relações e interações sem forma definida (LEATHLEY, 2007, p. 261-262).

Quando Koskenniemi aborda o problema de forma descritiva e como algo inevitável, mas ao mesmo tempo ressaltando a capacidade das ferramentas existentes no direito internacional de darem tratamento às questões emergentes, ele expõe a questão da fragmentação como uma questão de técnica jurídica, a ser equacionada por um conjunto de ferramentas jurídicas cujo desenvolvimento é parte da tarefa do Grupo de Estudos. Essa forma de perceber o fenômeno, no entanto, naturaliza a fragmentação e ao mesmo tempo revela uma percepção instrumental do direito internacional, que é vista como uma ameaça à efetivação dos valores superiores dos quais esse ramo do direito é vetor, ao mesmo tempo que mantém a posição de proeminência dos Estados enquanto atores e autores do direito internacional. Tem-se então, a enriquecer o debate sobre a fragmentação também uma colisão entre visões de mundo e ideologias relativas à função do direito internacional.

Afinal, o fenômeno da fragmentação é positivo ou negativo? Reforça ou enfraquece o papel do direito internacional no mundo contemporâneo? É um fato a ser compreendido ou uma ideologia a ser combatida ou adotada? A Comissão entendeu por bem tratá-la como um fenômeno com aspectos positivos e negativos, que ocorre no contexto de um mundo plural e cujos desafios não são de modo REVISTA DO DIREITO UNISC, SANTA CRUZ DO SUL № 40| p. $184-229$ | AGO - OUT 2013 
algum desconhecidos, novos ou não passíveis de serem tratados pelas ferramentas desenvolvidas pela técnica do direito internacional para solucionar os conflitos normativos que já ocorreram no passado e enfrentar as dificuldades de efetivação que os conflitos normativos trazem à ordem internacional (ILC, 2006, p. 405).

Esse estado fragmentário, inerente ao direito internacional, não é uma realidade até então inexistente que foi desencadeada pela II Guerra Mundial e pelos eventos que a ela se seguiram. É mais lógico supor, ao contrário, que até então o caráter amorfo do direito internacional fosse encarado com normalidade e que, a partir da criação de uma organização internacional de caráter universal e com pretensões de harmonizar a prática das relações internacionais e sistematizar o sistema jurídico que o regulava, a realidade fragmentada tenha apresentado resistência ao projeto de organização e sistematização da segunda metade do século XX. Dessa perspectiva, o fenômeno novo e perturbador da ordem internacional não é a fragmentação, mas o projeto jurídico de ordenar e sistematizar, atribuindo unidade a uma ordem jurídica inerentemente plural.

Por causa disso, essa divergência teórico-ideológica pode ser percebida como uma reedição ou continuação do debate entre Kelsen e Triepel, entre monismo e dualismo, que desde o final do século XIX opõe jusinternacionalistas que concebem o direito internacional como um sistema composto de uma pluralidade de realidades jurídicas e aqueles que o percebem como um todo hierarquizado e coerente. Os primeiros vêem na pluralidade do direito internacional uma característica funcional, coerente com a multiplicidade de seus atores; os segundos percebem tal pluralidade como desagregadora e produtora de incoerência. Para os primeiros, a composição de uma ordem jurídica internacional unificada ameaça a soberania dos Estados e é um projeto que levará os Estados a desertar dessa ferramenta de interação que é o direito internacional. Para os segundos, uma ordem jurídica unificada é a barreira necessária que a humanidade deve opor ao exercício ilegal da soberania e, como tal, deve ter fundamento e existência independente das vontades e conveniências dos Estados.

A primeira conclusão apresentada pelo Grupo de Estudos - a de que o direito internacional é um sistema jurídico - é mais um postulado que uma conclusão propriamente dita. É um postulado sujeito a disputas, causadas justamente pela possibilidade do de que o direito internacional não seja, no fim das contas, um № 40|p. $184-229$ | AGO - OUT 2013 
sistema, ou ainda mais, um sistema coerentemente organizado, à moda dos sistemas de direito interno. O Grupo de Estudos da Comissão de Direito Internacional apresentou um postulado normativo para responder a uma questão ontológica e, a partir daí, responder às questões técnicas relativas às interações entre as normas de direito internacional (MICHAELS; PAUWELYN, 2012, p. 349).

Isso demonstra como o antigo debate entre monismo e dualismo continua aceso. No entanto, revela também que a discussão teórico-epistemológica acerca da natureza do direito internacional, por fascinante que seja, é insolúvel e pode contaminar os aspectos mais simples e operacionais da questão e comprometer a sua resolução.

Para Michaels \& Pauwelyn, a discussão ontológica acerca do caráter unitário ou plural, sistemático ou fragmentado do direito internacional, tem sua importância superestimada, pois os principais problemas relativos à fragmentação são técnicos e não normativos, dizem eles:

There exists a widespread normative preference for coherence over fragmentation, order over disorder, system over plurality. We do not go so far as to claim that the question of whether international law is a coherent system or not is normatively irrelevant. However, we do think that its normative implications are overrated, and that the main problems with fragmentation are technical, not normative, in nature. If the resolution of conflicts were only possible within a coherent system, then the question of whether international law is such a system would have direct normative implications. If, by contrast, it can be shown that conflicts can be resolved also in the absence of one coherent system, then what looked like a normative question becomes a technical one: the prime question is then which of different types of technical rules we have to apply to deal with the conflict (MICHAELS; PAUWELYN, 2012, p. 350).

Com relação aos tipos de regras a serem usadas na resolução de conflitos, o relatório analítico ressaltou a utilidade de atentar para as ferramentas tradicionais do direito internacional, são regras que se referem a conflitos dentro de um sistema jurídico, chamados de conflitos normativos (conflicts of norms). O uso dessas regras pressupõe que o direito internacional é um sistema comparável aos sistemas jurídicos nacionais (MICHAELS; PAUWELYN, 2012, p. 350).

Indeed, it appears scholars often want to see international law as a system (rather than a pluralist or fragmented agglomeration) in part because this 
makes it possible to apply traditional conflict of norms rules (such as the principles of lex posterior or lex specialis). When the report of the ILC Study Group discusses ideas of legal pluralism, for example, it does so with the concern that such pluralism will be incompatible with the systematic approach and the rules on conflict of norms it encompasses. Its main author, Martti Koskenniemi, has elsewhere expressed his normative concerns over such Pluralism (MICHAELS; PAUWELYN, 2012, p. 351).

No entanto, há outras regras tradicionais para lidar com conflitos no direito internacional que não as regras para conflitos normativos intra-sistêmicos, são as regras para conflitos entre sistemas legais, as regras do direito internacional privado (conflict of laws).

De acordo com Michaels \& Pauwelyn:

Such conflict-of-laws rules have occasionally been considered for public international law, too. In 1953, Wilfred Jenks argued that "some of the problems which [conflicts between treaties] involve may present a closer analogy with the problem of the conflict of laws than with the problem of conflicting obligations within the same legal system." Philip Jessup, in his famous lectures on transnational law, also discussed the problem of applicable laws before international tribunals as one of choice of law and compared it explicitly with the task of the national judge in determining which law to apply. More recently, Andreas Fischer-Lescano and Gunther Teubner have developed the idea that the national differentiation of law is now overlain by a sectoral differentiation and that conflicts between sectoral lawsregimes-must, like conflicts between national laws, be dealt with through a system of conflict of laws (MICHAELS; PAUWELYN, 2012, p. 351-352).

No entanto, os autores em seguida enfatizam que não existem discussões desenvolvidas sobre quando e como uma abordagem de direito internacional privado poderia ajudar a resolver conflitos de direito internacional público. Eles atribuem o pouco desenvolvimento das discussões no setor ao fato de os autores no campo assumirem que o direito internacional é ou deve ser um sistema coerente, derivando daí suas conclusões (MICHAELS; PAUWELYN, 2012, p. 352).

Em diversos campos do direito internacional, as normas gerais tornaramse insuficientes para definir o padrão de conduta adequado. $O$ que se pode dizer, em outras palavras, é que o direito internacional passou a adotar um papel regulatório mais minucioso e disso decorreu uma expansão na quantidade de normas, uma diversificação de sua temática e também uma variação na sua força 
normativa. Essa evolução foi encarada com alguma preocupação, uma vez que apontava para rumos não previstos pelo direito internacional da forma como concebido até a metade do século $X X$.

Uma das expressões mais nítidas dessas preocupações foi 0 artigo publicado em 1982, por Prosper Weil, no American Journal of International Law. O artigo retratava as preocupações com a relativização das normas do direito internacional e com a diluição de suas fontes produtores em uma diversidade de fontes mais ou menos fortes e relativamente independentes do controle estatal normas de jus cogens, obrigações erga omnes, costume instantâneo (WEIL, 1983). Essas mesmas preocupações foram retomadas no Curso Geral que Weil ministrou na Haia em 1992 (WEIL, 1992).

No relatório analítico, Koskenniemi esclarece o que é conflito de normas e procura demonstrar como ele ocorre no direito internacional. Ele chega a ressaltar que não apenas há um conflito potencial, como também há uma competição entre regimes especializados, cada um deles revelando uma tendência própria e cada um deles sendo objeto de promoção ou objeção política dos Estados à medida que são úteis para a promoção de suas respectivas agendas.

Talvez seja essa visão da utilização do direito como uma ferramenta para promoção dos interesses dos Estados que gere maior debate entre os leitores do relatório. A questão pode ser colocada como um capítulo na disputa filosófica relativa ao papel do direito internacional, se de instrumento ou de limite do exercício da soberania dos Estados. Parece que Martii Koskenniemi aceita uma duplicidade no papel do direito que, no mínimo, incomoda e ameaça a concepção do direito orientada por valores superiores e, no máximo, é errada por ser simplesmente incompatível com essa visão. Mas a visão de Koskenniemi comporta também a ideia de que a especialização do direito internacional e a concorrência entre sistemas normativos especializados pode ser abordada ao largo das questões estratégicas nacionais e vista pelo ângulo técnico-formal da aplicação do direito.

Desse ponto de vista, a fragmentação é um fenômeno a ser superado pelo desenvolvimento de ferramentas técnicas e conceituais capazes de determinar, à margem das preferências político-ideológicas dos apoiadores da expansão de determinados regimes, qual a jurisdição competente para os conflitos que envolvam o direito internacional e quais as regras aplicáveis para sua solução.

REVISTA DO DIREITO UNISC, SANTA CRUZ DO SUL № 40|p. $184-229$ | AGO - OUT 2013 


\section{CONSIDERAÇÕES FINAIS}

Mais adequado que a expressão fragmentação do direito internacional é falar de diversificação e expansão do direito internacional. A primeira expansão assume uma conotação eminentemente negativa, a segunda parece referir mais fielmente um fenômeno que, independentemente de nossas expectativas acerca do mesmo, está a ocorrer.

É difícil compreender a emissão de juízos de valor acerca do fenômeno da diversificação e expansão do direito internacional, a não ser que estas sejam percebidas como posicionamentos decorrentes da adoção de uma visão normativa, que preconiza que o direito internacional deve ser sistemático, unitário e coerente e que a fragmentação representa uma patologia desse sistema.

Os resultados do Grupo de Estudos reafirmaram o caráter unitário e sistêmico do direito internacional. Mesmo em um contexto de fragmentação, esse caráter é assegurado pelo direito internacional geral, que jaz como pano de fundo para todas as normas, sistemas e subsistemas do direito internacional. É de se notar que o relatório analítico e as conclusões, ainda que tenham buscado afastar-se de digressões teóricas, assumiram um ponto de vista ontológico em relação ao direito internacional, pelo qual este é ou deve ser uma ordem jurídica.

O direito internacional geral, em um contexto de expansão e diversificação do direito internacional, tem sua importância ampliada, como ferramenta para a construção de soluções técnicas para solução de antinomias.

Todas as soluções dadas pelo direito internacional geral, ou melhor, pela aplicação do direito internacional geral pelas instituições competentes, devem ser encaradas como soluções tópicas, cujos fundamento e construção argumentativa não pode ter a pretensão de cristalizar e imobilizar concepções acerca do direito internacional.

O direito internacional é um fenômeno dinâmico cujas mudanças correspondem às necessidade e agendas distintas dos vários atores internacionais.

A expansão e diversificação do direito internacional é um fenômeno decorrente da evolução deste ramo do direito, não uma indicação de seu fim. Portanto, deve ser vista como a busca da realização de oportunidades históricas de № $40 \mid$ p. $184-229$ | AGO - OUT 2013 
desenvolvimento do direito internacional, mas também como a proposição de renovados desafios com relação à manutenção do caráter sistêmico e unitário do direito internacional.

Por fim, a utilização de ferramentas típicas do direito internacional privado não deve ser descartada como um novo capítulo que se abre para pesquisas e discussões acerca da resolução de conflitos entre os subsistemas do direito internacional.

\section{REFERÊNCIAS}

DELBRÜCK, J. A more effective international law or a new "world law": Some aspects of the development of international law in a changing international system. Indiana Law Journal, v. 68, n. 3, Summer 1993, p. 705-725. Disponível em: < http://www.repository.law.indiana.edu/ilj/vol68/iss3/8>. Acesso em 1 ago. 2013.

FRY, E. H. Sovereignty and federalism: U.S. and Canadian perspectives. Challenges to sovereignty and governance. Canada-United States Law Journal, v. 20, 1994, p. 303-317.

Disponível

em:

<http://search.ebscohost.com/login.aspx?direct=true\&db=afh\&AN=9707062698\&lang =pt-br\&site=ehost-live>. Acesso em 1 ago. 2013.

GUGGENHEIM, Paul. Les Principes de Droit International Public. Recueil des Cours, v. 80, p. 1-189, 1952.

HAFNER, Gerhard. Risks ensuing from fragmentation of international law. In: INTERNATIONAL LAW COMMISSION (ILC). Report of the fifty-second session (2000). A/55/10. Disponível em: <http://untreaty.un.org/ilc/reports/2000/repfra.htm>. Acesso em 8 jan. 2013.

. Report of the fifty-second session (2000). A/55/10. Disponível em: <http://untreaty.un.org/ilc/reports/2000/repfra.htm>. Acesso em 8 jan. 2013.

Report of the fifty-fourth session (2002). A/57/10. Disponível em: <http://untreaty.un.org/ilc/reports/2002/2002report.htm>. Acesso em 8 jan. 2013.

Report of the fifty-fifth session (2003). A/58/10. Disponível em:

<http://untreaty.un.org/ilc/reports/2003/2003report.htm>. Acesso em 8 jan. 2013.

Report of the fifty-sixth session (2004). A/59/10. Disponível em: <http://untreaty.un.org/ilc/reports/2004/2004report.htm>. Acesso em 8 jan. 2013. 
Report of the fifty-seventh session (2005). A/60/10. Disponível em: <http://untreaty.un.org/ilc/reports/2005/2005report.htm>. Acesso em 8 jan. 2013.

Report of the fifty-eighth session (2006). A/61/10. Disponivel em: <http://untreaty.un.org/ilc/reports/2006/2006report.htm>. Acesso em 8 jan. 2013. KOSKENNIEMI, Martii. Fragmentation of International Law: difficulties arising from the diversification and expansion of international law. Geneva: International Law Comission (United Nations), 2006. 256 p.

LEATHLEY, Christian. An institutional hierarchy to combat the fragmentation of international law: has the ILC missed an opportunity? New York University Journal of International Law and Politics. v. 40, n. 1, Fall, 2007. p. 259-306. Disponível em: <http://heinonline.org>. Acesso em 2 ago. 2013.

MATHESON, Michael T. The Fifty-Seventh Session of the International Law Commission. The American Journal of International Law, v. 100, n. 2, apr. 2006, p. 416-428. Disponível em: <http://www.jstor.org/stable/3651154>. Acesso em 28 dez. 2012.

. The Fifty-Eighth Session of the International Law Commission. The American Journal of International Law, v. 101, n. 2, apr. 2007, p. 407-441. Disponível em: <http://www.jstor.org/stable/4492898>. Acesso em 28 dez. 2012. MICHAELS, Ralf; PAUWELYN, Joost. Conflict of norms or conflict of laws?: different techniques in the fragmentation of public internatinal law. Duke Journal of Comparative and International Law. v. 22. 2012. p. 349-376. Disponível em: <http://heinonline.org>. Acesso em 15 jan. 2013.

ODENDAHL, Kerstin. Article 30. In: DÖRR, Oliver; SCHMALENBACH, Kirsten. Vienna Convention on the Law of Treaties: A Commentary. Berlin: Springer, 2012. 1423p. p. 504-516.

REISMAN, W. M. International law after the cold war. American Journal of International Law, v. 84, n. 4, oct. 1990, p. 859-866. Disponível em: <http://wwwjstor-org.ez83.periodicos.capes.gov.br/stable/2202837>. Acesso em 1 ago. 2013.

REZEK, Francisco. Direito Internacional Público: Curso Elementar. 13.ed. São Paulo: Saraiva, 2011. 463p.

ROSENSTOCK, Robert. The Fifty-Second Session of the International Law Commission. The American Journal of International Law, v. 95, n. 1, jan. 2001, p. 
221-226. Disponível em: <http://www.jstor.org/stable/2642063>. Acesso em 28 dez. 2012.

ROSENSTOCK, Robert; GRIMES, Benjamin K. The Fifty-Fourth Session of the International Law Comission. The American Journal of International Law, v. 97, n. 1, jan. 2003, p. 162-167. Disponível em: <http://www.jstor.org/stable/3087112>. Acesso em 28 dez. 2012.

SIXTH COMMITTE (LEGAL). Topical summary of the discussion held in the Sixth Committee of the General Assembly during its fifty-eighth session, prepared by the Secretariat (2004). A/CN.4/537. Disponível em: <http://daccessdds-ny.un.org/doc/UNDOC/GEN/N04/216/84/PDF/N0421684.pdf?OpenElement>.

Acesso em 10 jan. 2013.

VARELLA, Marcelo D. Direito Internacional Público. 4.ed. São Paulo: Saraiva, 2012. $561 p$.

WEIL, Prosper. Towards Relative Normativity in International Law? American Journal of International Law. v. 77, n. 3, jul. 1983. p. 413-442. Disponível em: <http://www.jstor.org/stable/2201073>. Acesso em 28 dez. 2012. . Le droit international en quête de son identité. Recueil des cours, v. 237, p. 9-370, 1992. 